\title{
Análises das concentrações de açúcares, cloreto de sódio e sódio nas águas de coco in natura e industrializadas comercializadas em Governador Valadares-MG
}

\section{Analysis of the concentrations of sugars, sodium chloride and sodium in fresh and industrialized coconut water commercialized in Governador Valadares-MG}

\section{Brenda Da Silva Soares}

Acadêmica do Curso de Nutrição da Universidade Vale do Rio Doce

E-mail: brenda.soares@univale.br

\section{Caroline Souza Vieira Neves}

Acadêmica do Curso de Nutrição da Universidade Vale do Rio Doce

E-mail: caroline.neves@univale.br

\section{Ana Clara De Alvarenga Morais}

Orientadora Professora Mestre do Curso de Nutrição da Universidade Vale do

Rio Doce

E-mail: ana.morais@univale.br

\section{Anderson Ferreira Vilela}

Professor do Curso de Agroindústria da Universidade Federal da Paraíba

E-mail: prof.ufpb.anderson@gmail.com

\section{Eloísa Helena Medeiros Cunha}

Orientadora Professora Mestre do Curso de Nutrição da Universidade Vale do Rio Doce

E-mail: eloisa_medeiros@hotmail.com

\section{RESUMO}

Introdução: Água de coco é a bebida não diluída, não fermentada, obtida da parte líquida do fruto do coqueiro, por meio de processo tecnológico adequado. O coco é uma das frutas mais populares do Brasil, no país o fruto tem utilização agroindustrial e culinária, através do albúmen sólido e também em sua forma in natura. Objetivos: O presente estudo teve como objetivo avaliar os teores de açúcares, sal (cloreto de sódio) e sódio em amostras de águas de coco in natura e industrializadas e compará-las com o descrito na legislação, assim como, as industrializadas com a rotulagem nutricional. Metodologia: Foi realizado um estudo analítico do tipo experimental qualitativo e quantitativo. Realizando análises de glicídios redutores em glicose e glicídios não redutores em sacarose, glicídios totais, cloreto de sódio e sódio. Para análise dos dados utilizou-se o software estatístico $R$ versão 3.4.1. Resultados: Verificou-se com o estudo que em relação a legislação, todas as amostras de água de coco (in natura e industrializadas) estavam dentro dos padrões vigentes para todas as análises 
realizadas, contudo, as rotulagens nutricionais não apresentaram os valores condizentes com os valores das análises e apresentaram quantidade superiores de açúcar em comparação com as águas in natura. Conclusão: Destacando a importância dos rótulos pois eles oferecem informações nutricionais, dos ingredientes utilizados na fabricação, para melhor escolha do produto.

Palavras-chave: Água de coco, Legislação,Rotulagem nutricional, Sódio, Açúcares.

\section{ABSTRACT}

Coconut water is the undiluted, unfermented beverage obtained from the liquid part of the coconut tree fruit, through an appropriate technological process. Coconut is one of the most popular fruits in Brazil, in the country the fruit has agro-industrial and culinary use, through solid albumen and also in its in natura form. The present study aimed to evaluate the contents of sugars, salt (sodium chloride) and sodium in samples of fresh and industrialized coconut waters and compare them with those described in the legislation, as well as those industrialized with nutritional labeling. An analytical study of qualitative and quantitative experimental type was carried out. Performing analyses of reducing glycides in glucose and non-reducing glycides in sucrose, total glycides, sodium chloride and sodium. Statistical software $R$ version 3.4.1 was used for data analysis. It was verified with the study that in relation to the legislation, all samples of coconut water (fresh and industrialized) were within the current standards for all analyses performed, however, nutritional labels did not present the values consistent with the values of the analyses and presented higher amounts of sugar compared to fresh waters. Highlighting the importance of labels because they offer nutritional information, of the ingredients used in manufacturing, for better product choice.

Keywords: Coconut water, Legislation, Nutrition labeling, Sodium, Sugars.

\section{INTRODUÇÃO}

O coco é o fruto do coqueiro (Cocos nucifera L.), sendo uma das frutas mais populares do Brasil. No país o fruto tem utilização agroindustrial e culinária através do albúmen sólido para a produção de leite de coco, farinha de coco, óleo de coco, e principalmente em sua forma in natura. A parte líquida do coco verde, conhecida como água de coco, é uma bebida estéril, rica em proteínas, vitaminas, açúcares e sais minerais (ARAGÃO, 2004).

Conforme a definição descrita no art. 20, do Decreto ํㅜ 6.871, de 4 de junho de 2009, água de coco é a bebida não diluída, não fermentada, obtida da 
parte líquida do fruto do coqueiro, por meio de processo tecnológico adequado (BRASIL, 2009).

De acordo com a Instrução Normativa nº 9, de 30 de janeiro de 2020 do Ministério da Agricultura, a água de coco é classificada e denominada como: água de coco integral que é o produto na sua concentração natural, sem a adição de água ou de açúcares; água de coco padronizada que é o produto obtido da padronização da água de coco integral, podendo ser adicionado de água de coco concentrada, água de coco desidratada e açúcares; água de coco reconstituída que é o produto obtido da reconstituição da água de coco concentrada ou desidratada, com adição de água potável ou água de coco integral, ou ambos, podendo ser adicionada de açúcares; água de coco desidratada que é o produto submetido a um processo adequado de desidratação da água de coco integral, cujo teor de umidade seja igual ou inferior a 5,0\% (cinco por cento); água de coco concentrada que é o produto submetido a um processo adequado de concentração da água de coco integral, sem adição posterior de água potável, cujo teor de sólidos solúveis mínimos seja igual a 30\% (trinta por cento) (BRASIL, 2020).

A água do coco verde vem sendo usada como uma alternativa de repositor de eletrólitos durante sessões de atividades físicas devido à sua composição físico-química que é rica em sais minerais, aminoácidos, proteínas, vitaminas e minerais (PINTO et al., 2015).

O consumo de produtos naturais cada vez mais vem ganhando espaço na população brasileira, com o objetivo de buscar uma vida mais saudável. Por isso a comercialização da água de coco vem crescendo cada vez mais, pois além de saciar a sede, sendo um substituto da água, ela também repõem os eletrólitos essenciais em quadros de desidratação, e seu uso é bastante frequente em locais de clima quente (NETO; LEITE; MARQUES, 2020).

Para manter sua estabilização e conservação a água de coco passa por processos industriais, assim é possível aumentar seu período de prateleira. Além disso adicionar alguns constituintes realça seu sabor. Nesses processos 
industriais pode haver algumas alterações no valor nutricional e por isso há o acréscimo de alguns nutrientes (NETO; LEITE; MARQUES, 2020).

Alguns estudos mostram que há uma falta de padrões de qualidade na comercialização e consumo de água de coco, de modo que compromete a saúde e a qualidade de vida da população (NETO; LEITE; MARQUES, 2020).

Entre os compostos da água de coco estão presentes os minerais como potássio e sódio. $O$ aumento pela busca de praticidade faz com que muitas vezes os consumidores optem pela água industrializadas em substituição à in natura, o que torna um fator preocupante devido as quantidades de sódio contidas nelas, sendo o limite regulamentado de 2 a $30 \mathrm{mg}$ por $100 \mathrm{~mL}$ (BRASIL, 2020). O elevado consumo de sódio ocasiona hipertensão arterial e doenças renais, fatores que podem comprometer a saúde da população (NOGUEIRA et al., 2004). Não só o sódio, mas também o elevado nível de açúcares na composição da água de coco processada, devem seguir o que é determinado pela legislação vigente. (BRASIL, 2020).

Perante a legislação, a adição de açúcares nas águas de coco padronizada e reconstituída não deverá ultrapassar os valores de $0,5 \mathrm{~g}$ por 100 $\mathrm{mL}$ do produto final (BRASIL, 2020), podendo também ser usada como bebida para esportes, por ser fonte de açúcares e repositor hidroeletrolítico (PINTO et al., 2015).

Desse modo, o presente estudo teve como objetivo avaliar os teores de açúcares, sal (cloreto de sódio) e sódio em amostras de águas de coco in natura e industrializadas comercializadas em Governador Valadares-MG e compará-las com o descrito na legislação, assim como, as industrializadas com a rotulagem nutricional.

\section{MATERIAIS E MÉTODOS}

Estudo analítico do tipo experimental qualitativo e quantitativo.

Local e Período da Pesquisa

A pesquisa foi realizada no Núcleo de Ciências da Saúde na Universidade Vale do Rio Doce (UNIVALE), situada na cidade de Governador Valadares-MG, 
no Laboratório de Farmacognosia e Laboratório de Farmacotécnica. As águas de coco foram coletadas e analisadas no período de setembro a outubro de 2021.

\section{DELINEAMENTO EXPERIMENTAL}

Foram coletadas 8 amostras de água de coco comercializadas em Governador Valadares-MG. As águas de coco foram adquiridas em duas formas de comercialização: in natura e industrializada. Foram utilizadas 4 marcas diferentes de água de coco industrializadas, as quais foram classificadas para 0 delineamento em (A, B, C e D) e 4 amostras de água de coco in natura, encontradas em 4 pontos de comercialização diferentes no centro da cidade, as quais também foram classificadas para o delineamento em ( $A, B, C$ e D). No presente estudo foram utilizadas as águas de coco classificadas de acordo com a legislação como integral, padronizada e reconstituída (BRASIL, 2020).

\section{AQUISIÇÃO DA MATÉRIA-PRIMA}

As quatro amostras de água de coco industrializadas foram adquiridas em supermercados de Governador Valadares, sendo as únicas marcas disponíveis no local. As águas de coco in natura foram adquiridas em pontos de comercialização nas ruas, em locais diferentes, em carrinhos de vendedores ambulantes, no momento da aquisição as águas já se encontravam envasadas e armazenadas em garrafas, ou seja, não foi diretamente do coco. Foram coletadas em pontos específicos, onde os consumidores têm grande acesso.

As amostras foram coletadas, identificadas com selo contendo numeração específica para cada local e armazenadas em caixas isotérmicas (aproximadamente $7^{\circ} \mathrm{C}$ ) até o laboratório onde foram realizadas as análises.

\section{CARACTERIZAÇÃO FÍSICO-QUÍMICA DAS ÁGUAS DE COCO}

As águas de coco foram armazenadas sob congelamento (aproximadamente $5^{\circ} \mathrm{C}$ ), no Laboratório de Técnica Dietética da Univale para as 
análises de Glicídios Redutores em Glicose e Glicídios Não Redutores em Sacarose, Cloreto de Sódio.

Glicídios Redutores em Glicose e Glicídios Não Redutores em Sacarose

Foram utilizados para a determinação dos açúcares, os métodos de Glicídios redutores em glicose e Glicídios não redutores em sacarose segundo a metodologia de Fehling Sendo o resultado expresso em gramas de glicose e sacarose por $100 \mathrm{~g}$ da amostra (IAL, 2008).

\section{GLICÍDIOS REDUTORES EM GLICOSE}

Pesou-se $5 \mathrm{~g}$ da amostra em um béquer de $100 \mathrm{~mL}$. Foi transferido para um balão volumétrico de $100 \mathrm{~mL}$ com o auxílio de água destilada. Completou-se o volume e agitado. Em um frasco Erlenmeyer de $250 \mathrm{~mL}$. Transferiu-se o filtrado para a bureta. Logo após foi colocado em um balão de fundo chato de $250 \mathrm{~mL}$, com auxílio de pipetas de $10 \mathrm{~mL}$, cada uma das soluções de Fehling $A$ e $B$, adicionando $40 \mathrm{~mL}$ de água destilada. Foi aquecido até a ebulição, adicionado, às gotas, a solução da bureta sobre a solução do balão em ebulição, agitando sempre, até que esta solução passou de azul para vermelho tijolo. Obtendo o resultado desejado.

\section{GLICÍDIOS NÃO REDUTORES EM SACAROSE}

Pesou-se de $5 \mathrm{~g}$ da amostra e transferiu-se para um balão volumétrico de $100 \mathrm{~mL}$ com auxílio de água destilada. Foi adicionado o ácido clorídrico (cerca de $1 \mathrm{~mL})$. Em seguida colocado em banho-maria a $(100 \pm 2){ }^{\circ} \mathrm{C}$ por 30 a 45 minutos. Foi esfriado e neutralizado com carbonato de sódio, foi adicionado à solução de hidróxido de sódio a 40\%, com auxílio de papel indicador, o volume foi completado com água destilada e agitado. O material foi transferido para a bureta. Em um balão de fundo chato de $250 \mathrm{~mL}$, com auxílio de pipetas de 10 $\mathrm{mL}$, cada uma das soluções de Fehling $\mathrm{A}$ e $\mathrm{B}$, adicionou-se $40 \mathrm{~mL}$ de água destilada. Foi deixado aquecer até que entrasse em ebulição. Foi adicionado, às gotas, a solução da bureta sobre a solução do balão em ebulição, agitando 
sempre, até que esta solução passou de azul para vermelho tijolo. Obtendo o resultado desejado.

\section{GLICÍDIOS TOTAIS}

Para análise de Glicídios Totais (\%) os valores foram adquiridos através do somatório de Glicídios Redutores em Glicose (\%) com os Glicídios Não Redutores em Sacarose (\%).

Cloreto de Sódio

Para determinação de Cloretos de Sódio foi utilizada a metodologia de argentométrico de Mohr, através da titulação com Nitrato de Prata (IAL, 2008).

Pesou-se $5 \mathrm{~g}$ da amostra, transferiu-se para um balão volumétrico de 500 $\mathrm{mL}$, com auxílio de $200 \mathrm{~mL}$ de água destilada, e foi deixado em repouso (até 2 horas), volume foi completado com água destilada e agitado. Transferiu-se, com auxílio de uma pipeta volumétrica, $10 \mathrm{~mL}$ dessa solução para um frasco Erlenmeyer de $250 \mathrm{~mL}$. Adicionou-se $50 \mathrm{~mL}$ de água destilada e 2 gotas de solução de cromato de potássio a 10\%. Foi feita a titulação com solução de nitrato de prata $0,1 \mathrm{M}$.

De acordo com a Associação Brasileira de Nutrição (2014), a cada 1g de sal equivale a $400 \mathrm{mg}$ de sódio. Portanto, os valores de cloreto de sódio encontrados nas amostras foram convertidos posteriormente em sódio, a conversão através das triplicatas e a média de valores de cada amostra para a comparação das análises das marcas industrializadas com a rotulagem nutricional e das amostras industrializadas e in natura com a legislação vigente.

Análise estatística

Os dados foram submetidos a análise de variância pelo teste $F(p \leq 0,05)$. As médias relativas a formas comercialização da água de coco e marcas foram comparadas pelo teste de Tukey $(p<0,05)$. Além disso, foi realizado o teste de contrastes ortogonais para comparar 0 tratamento in natura versus industrializado. Para análise dos dados utilizou-se o software estatístico Rversão 3.4.1. 


\section{RESULTADOS}

Observa-se que houve diferença $(p \leq 0,0001)$ nas amostras de água de coco industrializadas para os valores médios de açúcares redutores (AR), açúcares não redutores (ANR) e açucares totais (AT), mas o cloreto de sódio $(\mathrm{NaCl})$, independentemente das formas de comercialização da água de coco (in natura e industrializada) não houve alteração (Tabela 1).

Tabela 1. Resumo da comparação de médias, referentes a AR, ANR, AT e NaCl submetidas a diferentes marcas (A, B, C e D) e duas formas de comercialização da água de coco

\begin{tabular}{|c|c|c|c|c|c|}
\hline \multirow[b]{2}{*}{ Fontes de variação } & \multirow[b]{2}{*}{ GL } & \multicolumn{4}{|c|}{ Quadrado Médio } \\
\hline & & $\begin{array}{c}\mathrm{AR} \\
(\% \text { glicose })\end{array}$ & $\begin{array}{c}\text { ANR } \\
(\% \text { sacarose })\end{array}$ & $\begin{array}{c}\text { Açúcares totais } \\
(\%)\end{array}$ & $\begin{array}{l}\mathrm{NaCl} \\
(\%)\end{array}$ \\
\hline & & \multicolumn{4}{|c|}{ Água de coco in natura } \\
\hline Marcas & 3 & $0,025^{\mathrm{ns}}$ & $0,482^{\mathrm{ns}}$ & $0,379^{\mathrm{ns}}$ & $0,0002^{\mathrm{ns}}$ \\
\hline Resíduo & 8 & 0,021 & 0,146 & 0,108 & 0,0002 \\
\hline $\mathrm{CV}(\%)$ & & 2,94 & 13,54 & 4,26 & 25,75 \\
\hline & & \multicolumn{4}{|c|}{ Água de coco industrializada } \\
\hline Marcas & 3 & $13,238 * * *$ & $15,555^{* *}$ & $19,043^{* *}$ & $0,0003^{\mathrm{ns}}$ \\
\hline Resíduo & 8 & 0,238 & 1,190 & 0,913 & 0,0001 \\
\hline $\mathrm{CV}(\%)$ & & 6,20 & 15,82 & 6,47 & 27,91 \\
\hline \multicolumn{6}{|l|}{ Contrastes Água de coco } \\
\hline Natural $v s$ industrializada & - & $* * *$ & $* * *$ & $* * *$ & ns \\
\hline Média & - & $6,37 \pm 2,04$ & $4,86 \pm 2,62$ & $11,23 \pm 3,99$ & $0,045 \pm 0,01$ \\
\hline
\end{tabular}

Analisando os contrastes ortogonais entre as formas de comercialização da água de coco (in natura e industrializado), observa-se que as variáveis açúcares redutores (AR), açúcares não redutores (ANR), açúcares totais (AT) foram influenciadas $(p>0,001)$ pelos consumos de água de coco in natura e/ou industrializado, no entanto, o cloreto de sódio não sofreu efeito do fator "água de coco" (Tabela 1). Observa-se que os valores de açúcares redutores, não redutores e totais na forma de comercialização de água de coco industrializado foram superiores ao o in natura dando resultado significativo à análise.

Observa-se (Figura 1) que os valores de açúcares redutores nas águas de coco in natura não apresentaram diferenças significativas, sendo os valores "A" (4,79\%), "B" (4,80\%), "C" (4,94\%) e "D" (4,96\%). (Figura 1a). 
Figura 1. Valores médios ( $\pm \mathrm{EP})$ de açúcares redutores (\% glicose) de diferentes marcas de água de $\operatorname{coco}(A, B, C$ e $D)$ e duas formas de comercialização da água de coco, água de coco, in natura

⿴囗十 industrializada

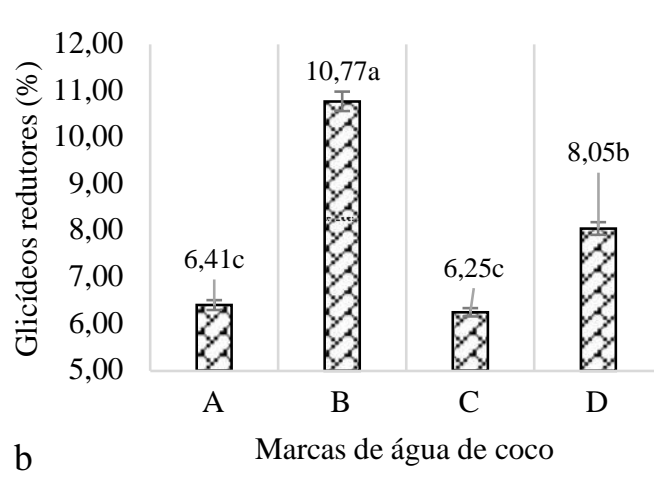

In natura

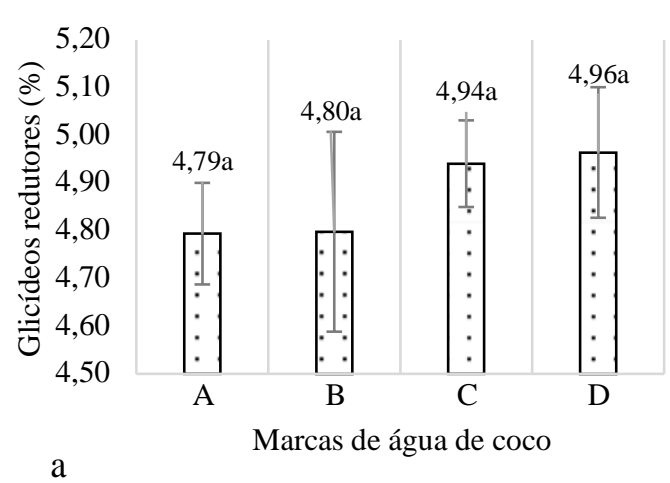

Fonte: Elaborado pelo autor (2021).

A.B Médias seguidas por diferentes letras minúsculas diferem de acordo com o teste Tukey $(p<0,05)$ para marcas do produto.

Considerando a forma de comercialização de água de coco industrializada (Figura 1b), observa-se que a marca denominada "B" (10,77\% glicose) apresentou maior valor médio de açúcares redutores em relação as marcas " $A$ " (6,41\% glicose) e "C" (6,25\% glicose), a marca "D" (8,05\% glicose) apresentou o segundo maior valor em relação as outras marcas.

A comparação entre médias apresentadas na Figura 2 mostra que os valores de açúcares não redutores em sacarose nas águas de coco na forma in natura não apresentaram valores significativamente diferentes nas amostras $A$ $B, C$ e $D(2,23 \pm 3,11)$. Observa-se que os valores da água de coco em sua forma industrializadas nas marcas "C" (8,54\% sacarose) e "D" (9,17\% sacarose) apresentou valores maiores em relação as marcas "A" (4,89\% sacarose) e "B" $(4,99 \%$ sacarose) (Figura $2 b)$. 
Figura 2. Valores médios ( $\pm E P$ ) de açúcares não redutores (\% sacarose) duas formas de comercialização da água de coco, água de coco, in natura (a) e

๒ industrializada

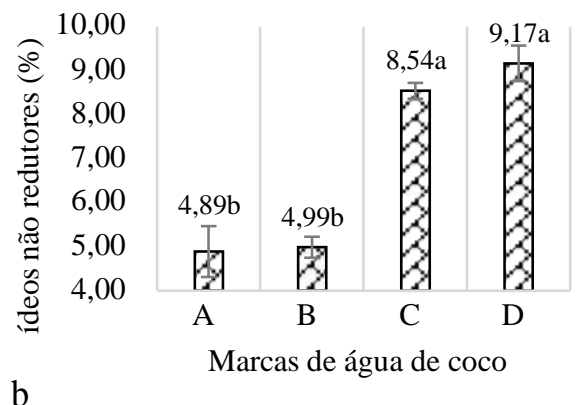

industrializada (b).

In natura

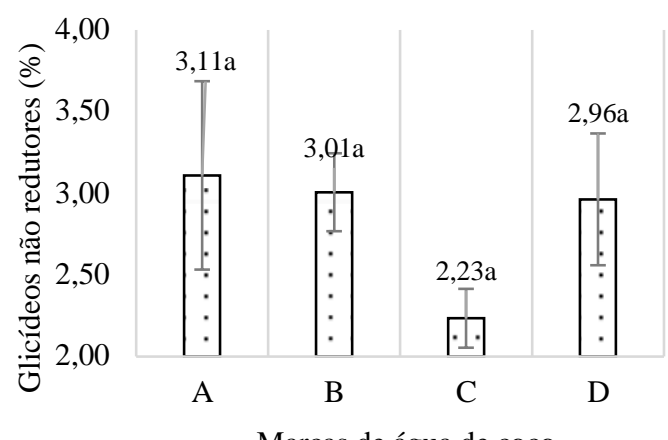

a

Marcas de água de coco

Fonte: Elaborado pelo autor (2021).

A.B Médias seguidas por diferentes letras minúsculas diferem de acordo com o teste Tukey $(p<0,05)$ para marcas do produto.

A comparação entre médias apresentada na Figura 3 mostra que os valores referentes aos açúcares totais das águas de coco in natura não apresentaram diferença significativa entre as amostras $(7,92 \pm 7,17 \%$ açúcares totais). Com relação aos valores encontrados das águas de coco industrializadas também não apresentaram diferenças significativa entre as amostras, sendo os valores "A" (11,29\% açúcares totais), "B" (15,76\% açúcares totais), "C" (14,79\% açúcares totais) e "D" (17,22\% açúcares totais). 
Figura 3. Valores médios ( $\pm E P)$ de açúcares totais (\%) duas formas de comercialização da água de coco, água de coco, in natura (a) e industrializada (b).
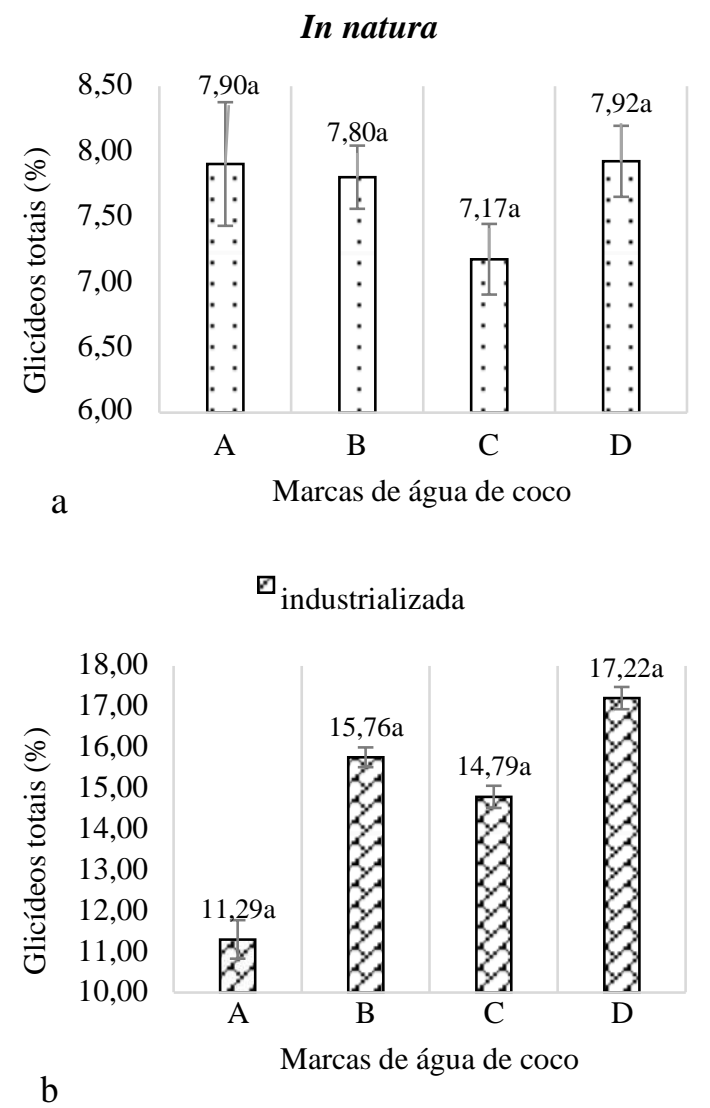

Fonte: Elaborado pelo autor (2021).

A.B Médias seguidas por diferentes letras minúsculas diferem de acordo com o teste Tukey $(p<0,05)$ para marcas do produto

A comparação entre médias apresentada na Figura 4 mostra que os valores referentes a análise de cloreto de sódio nas amostras de água de coco in natura e industrializadas não apresentaram diferenças entre as amostras, onde os valores variaram de 0,043 a 0,061 nas águas de coco in natura e 0,035 a 0,050 nas industrializadas. 
Figura 4. Valores médios ( $\pm \mathrm{EP})$ de cloreto de sódio (\%) duas formas de comercialização da água de coco, água de coco, in natura (a) e industrializada (b).

\section{In natura}

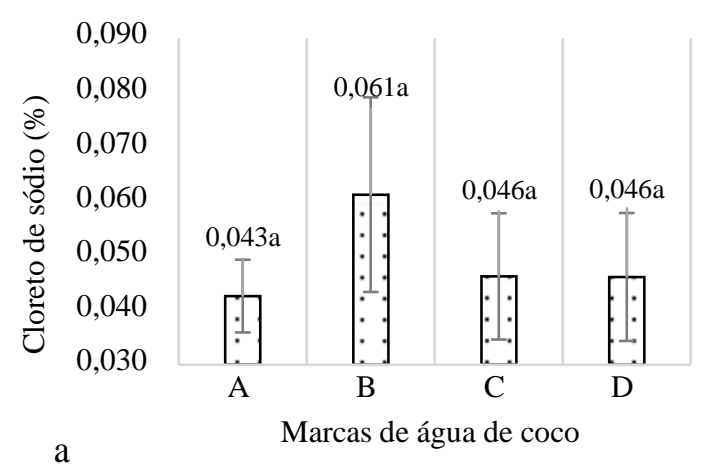

$\square_{\text {industrializada }}$

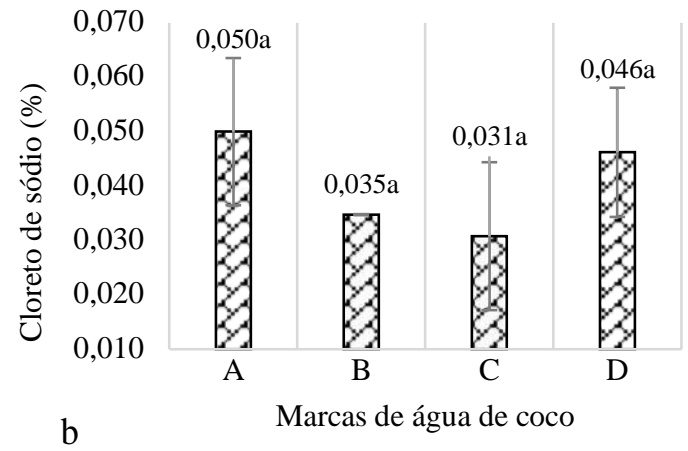

A.B Médias seguidas por diferentes letras minúsculas diferem de acordo com o teste Tukey $(p<0,05)$ para marcas do produto.

Resultado da conversão de cloreto de sódio em sódio

$\mathrm{Na}$ Tabela 2, é mostrado os valores da conversão de cloretos de sódio em sódio das amostras de água de coco in natura e industrializadas. Pode-se observar que a amostra B da água de coco in natura apresentou valores mais elevados em comparação com as outras, sendo a amostra A com menor valor. Já em relação as águas de coco industrializadas, a amostra $A$ apresentou maior valor de sódio em comparação as outras amostras e a amostra B com menor valor. 
Tabela 2. Conversão de cloreto de sódio em sódio

\begin{tabular}{c|c|c}
\hline IN NATURA & Cloreto de Sódio (\%) & Sódio (mg/100g) \\
\hline A & 0,043 & $\mathbf{1 7 , 0}$ \\
\hline B & 0,061 & $\mathbf{2 4 , 5}$ \\
\hline C & 0,046 & $\mathbf{1 8 , 5}$ \\
\hline D & 0,046 & Sódio (mg/100g) \\
\hline INDUSTRIALIZADA & Cloreto de Sódio (\%) & $\mathbf{1 8 , 5}$ \\
\hline A & 0,050 & $\mathbf{1 3 , 9}$ \\
\hline B & 0,035 & $\mathbf{1 2 , 3}$ \\
\hline C & 0,031 & $\mathbf{1 8 , 5}$ \\
\hline D & 0,046 &
\end{tabular}

\section{DISCUSSÃO}

Glicídios redutores em glicose e Glicídios não redutores em sacarose

$\mathrm{Na}$ análise de Glicídios redutores em glicose (Figura 1) as amostras in natura não apresentaram valores significativamente diferentes entre asamostras. $\mathrm{Na}$ legislação não é descrito valores de açúcares redutores em glicose em amostras de água de coco na forma in natura e industrializadas.

O teor de açúcares redutores em glicose na água de coco variou de 6,25 a $10,77 \%$ nas amostras industrializadas, enquanto a água de coco in natura apresentou um teores mais baixos $(4,96 \pm 4,76 \%)$. Na literatura, os valores encontrados variam entre 0,62 e 4,92\%. (DUARTE, 2012).

$\mathrm{Na}$ amostra B (10,77\%) da água de coco industrializada constatou valor elevado, porém, como é permitido pela legislação, as águas de coco industrializadas podem receber açúcar durante seu processamento, não podendo ultrapassar de $0,5 \mathrm{~g} / 100 \mathrm{~mL}$ (BRASIL, 2020).

Com relação aos valores de glicídios não redutores em sacarose (Figura 2) as amostras in natura não apresentaram valores significativamente diferentes entre si. Já nos valores das águas de coco industrializadas as marcas "C" $(8,54 \%)$ e " $D$ " (9,17\%) apresentaram maiores valores em comparação com as amostras "A" (4,89\%) e "B" (4,99\%). Entretanto os valores medianos mais 
elevados nas águas industrializadas apontam adição de sacarose hidrolisada (FERREIRA; SILVA; PERRONE, 2001).

Sendo assim, as águas de coco industrializadas podem apresentar valores significativos devido a adição de sacarose no processamento da bebida (JACKSON et. al., 2004).

$\mathrm{Na}$ legislação vigente é mostrado os valores de açúcares na forma de sólidos solúveis em Brix que se refere aos valores de uma escala numérica que mede a quantidade de sólidos solúveis em uma solução de sacarose (BRASIL, 2020).

Os valores recomendamos pela legislação de açúcares em grau Brix deve apresentar nas águas de coco in natura e industrializadas valores de no mínimo 4,0 e máximo 29 , onde um grau Brix ( $\left(1^{\circ} \mathrm{Bx}\right)$ é igual a 1 grama de açúcar por 100 gramas de solução ou 1\% de açúcar (BRASIL, 2020). Sendo assim, os valores encontrados de açúcares não redutores em sacarose, tanto nas amostras de água de coco in natura quanto nas industrializadas, encontram-se dentro dos valores exigidos pela legislação.

Glicídios totais

A análise de glicídios totais (Figura 3), apresentou nas águas de coco in natura e industrializadas valores na mesma média. Nas águas de coco in natura as amostras apresentaram valores mais baixos $(7,17 \pm 7,92$ de glicídios totais) em comparação aos valores das águas de coco industrializadas que se apresentam bem mais altos $(11,29 \pm 17,22)$. Contudo, segundo a Instrução Normativa nº 9, de 30 de janeiro de 2020, a água de coco industrializada poderá ser adicionado açúcares em quantidades igual ou inferior a 0,5 g/ 100 ml (BRASIL, 2020).

Estes maiores teores, provavelmente, está relacionado à concentração de solutos ou adição de frutose durante padronização/ formulação para as amostra. O estudo de Costa et al. (2005) obteve resultados parecidos.

Fica difícil a comparação dos valores de açúcares totais com a legislação visto que não apresenta valores recomendados de açúcares totais em águas de coco na forma in natura e industrializada. A legislação relata somente que as águas de coco in natura não poderão ser adicionadas de açúcares e água, 
enquanto as industrializadas poderão ser adicionadas de açúcares, água, vitaminas, fibras, minerais e outros nutrientes (excetuando-se compostos fontes de sódio e potássio), partes comestíveis do coco, gás carbônico (industrialmente puro), maltodextrina, e aditivos desde que estejam especificados nos rótulos.

Glicídios totais em comparação com os rótulos

A rotulagem nutricional tem grande importância no fornecimento de informação sobre o produto para o consumidor, para cumprir a rotulagem de forma fidedigna depende também da equipe do setor industrial para o cuidado na produção (FIGUEIROA; OLIVEIRA, 2017).

Os valores de glicídios totais encontrados nas análises possuem diferença dos valores contidos nos rótulos das marcas. A marca "A" apresentou 11,29\% (rotulagem 5,42\%), "B" apresentou 15,76\% (rotulagem 5\%), na marca “C' 14,79\% (rotulagem 5,5\%) e "D" 17,22\% (rotulagem 5,5\%), sendo assim os valores contidos na rotulagem nutricional não conferem com as analisadas, estando os valores bastante aumentados, não cumprindo com a fidedignidade do produto e da marca. O estudo de Santos (2016) também obteve diferença entre os valores listados nos rótulos da embalagem com os resultados obtidos na sua análise.

Cloreto de sódio e sódio

De acordo com o que foi analisado (Figura 4), os valores referentes as amostras de água de coco in natura e industrializadas, não apresentaram diferença significativa entre si.

Os valores de cloreto de sódio encontrados nas amostras foram convertidos em sódio (Tabela 2).

As amostras das águas de coco in natura estão todas dentro do permitido pela legislação de 2 a $30 \mathrm{mg} / 100 \mathrm{~mL}$, sendo os valores das amostras de 17,2 a 24,4 mg (BRASIL, 2020).

Contudo, as amostras das águas de coco industrializadas também apresentaram os valores de sódio no dentro dos valores permitidos, sendo os valores das amostras de 12,4 a 20 mg. Já em relação dos valores da análise e 
os valores contidos na rotulagem nutricional todos as marcas apresentaram diferença nos valores das análises com os contidos no rótulo.

Neto, Leite e Marques (2020) discorrem que para manter o controle das amostras é necessário averiguação efetiva do teor descrito nas embalagens para que os consumidores tenham consciência e consigam mensurar o quanto estão ingerindo, pois o excesso desse elemento pode comprometer a saúde dos consumidores.

A marca "A" apresentou 20 mg/100 g (rotulagem 8 mg/100 ml), na marca "B" $14 \mathrm{mg} / 100 \mathrm{~g}$ (rotulagem $6 \mathrm{mg} / 100 \mathrm{ml}$ ), na marca "C" o valor da análise foi $12,4 \mathrm{mg} / 100 \mathrm{~g}$ (rotulagem $7 \mathrm{mg} / 100 \mathrm{ml}$ ) e na marca “D” 18,4 mg/100 g (rotulagem $7 \mathrm{mg} / 100 \mathrm{ml}$ ). Sendo assim, nenhuma das marcas apresentou valores próximos ao indicado no rótulo do produto, sendo de suma importância que as informações contidas nos rótulos sejam fidedignas, para que o consumidor tenha acesso as informações nutricionais de forma clara e adequada (FIGUEIROA; OLIVEIRA, 2017).

\section{CONCLUSÃO}

Conclui-se que os dados das amostras industrializadas dos valores de glicídios não redutores em sacarose e glicídios totais apresentaram valores alterados, porém estão em conformidade com a legislação vigente. Os valores de glicídios totais encontrados nas análises possuem diferença dos valores contidos nos rótulos das marcas.

Em relação aos valores de sódio tanto das amostras in natura quanto das industrializadas estão dentro dos valores permitidos pela legislação, porém quando analisado os resultados das análises e os valores descritos na informação nutricional dos rótulos, estas, apresentaram diferenças.

Portanto, é de suma importância ressaltar que as concentrações encontradas nos produtos sejam condizentes com o descrito no rótulo, pois estes trazem informações nutricionais, dos ingredientes utilizados na fabricação, para melhor escolha do produto. 
O nutricionista é um profissional de grande importância, tanto na produção dos alimentos industrializados garantindo a quantidade adequada contida nos rótulos, quanto para a incentivo à população a buscarem pelos melhores produtos através da leitura deles, priorizando alimentos com menos teores de açúcares e sódio, buscando prevenção de doenças e promoção de saúde. 


\section{REFERÊNCIAS}

Abreu, I. F. Et al. Perfil sensorial e aceitabilidade de amostras de água-de-coco obtidas por diferentes processos de fabricação. Boletim do centro de pesquisa de processamento de alimentos, v. 23, n. 2, 2005. Disponível em:

Https://revistas.ufpr.br/alimentos/article/viewfile/4477/3500. Acesso em 10 out. 2021.

Aragão, wilson menezes (ed.). Coco: pós-colheita. Brasília: embrapa informação tecnológica, 2002. 76 p. (frutas do brasil). Isbn 85-7383-146-4.

Aragão, w. M; isberner, i. V; cruz, e. M. De o. Água-de-coco. Embrapa tabuleiros costeiros, documento n. 24, 32p. Aracaju, 2001.

Aroucha, e. M.; vianni, r. Determinação de ácido ascórbico na água de coco por cromatografia líquida e pelo método titulométrico. Revista ceres, v. 49, p. 245252, 2002. Disponível em:

Http://www.ceres.ufv.br/ojs/index.php/ceres/article/view/2808. Acesso em: 30 set. 2021.

Brasil. Casa civil. Subchefia para assuntos jurídicos. Decreto $n^{\circ} 6.871$, de 4 de junho de 2009 regulamenta a lei no 8.918, de 14 de julho de 1994, que dispõe sobre a padronização, a classificação, o registro, a inspeção, a produção e a fiscalização de bebidas. Brasília, df, 2009.

Brasil. Ministério da agricultura, pecuária e abastecimento. Instrução normativa no 9, de 30 de janeiro de 2020. Estabelece os padrões de identidade e qualidade para a água de coco, bem como os respectivos parâmetros analíticos. Brasília, df, 2020.

Costa, I. M. C. Et al. Avaliação de água-de-coco obtida por diferentes métodos de conservação. Ciência e agrotecnologia, v. 29, p. 1239-1247, 2005. Disponível em:

https://www.scielo.br/j/cagro/a/cnjqhrvsqb7frvdgrkfbmfs/?lang=pt\&format=pdf. Acesso em: 01 out. 2021.

Duarte, c. S. S. Análise físico-química da água de coco (cocus nucifera I.) Nas formas industrializada e in natura do município de ariquemes-ro. Faculdade de educação e meio ambiente. Trabalho de monografia. Ariquemes-ro, 2012.

Ferreira, v. F.; silva, f. C.; perrone, c. C. Sacarose no laboratório de química orgânica de graduação. Química nova, v. 24, p. 905-907, 2001. Disponível em:

Https://www.scielo.br/j/qn/a/ygqhybxdnzh8zx4gzlkqsbc/?lang=pt. Acesso em 08 out. 2021. 
Figueiroa, g. F. O; oliveira, c. L. A. Avaliação de rótulos de embalagens de águas de coco comercializadas em natal, rn. Revista uni-rn, v. 17, n. 1/2, p. 30, 2017. Disponível em:

Http://revistas.unirn.edu.br/index.php/revistaunirn/article/download/480/375/. Acesso em 10 out. 2021.

lal. Instituto adolfo lutz. Métodos físico-químicos para análise de alimentos. 4 ed. 1 ed. Digital. São paulo: instituto adolfo lutz, 2008. 1020 p. Disponível em:

Http://www.ial.sp.gov.br/ial/publicacoes/livros/metodos-fisico-quimicos-paraanalise-de-alimentos. Acesso em: 16 out. 2021.

Jackson, j. C. Et al. Changes in chemical composition of coconut (cocos nucifera) water during maturation of the fruit. Journal of the science of food and agriculture, v. $84, \quad$ n. $9, \quad$ p. 1049-1052, 2004. Disponível em: https://onlinelibrary.wiley.com/doi/abs/10.1002/jsfa.1783. Acesso em 08 out. 2021.

Neto, i. F. S.; leite, i. B; marques, a. E. F. Análise da concentração de sódio de águas de coco in natura e processada comercializadas em juazeiro do norte, ce. Scientia naturalis, v. 2, n. 2, p. 478-487, 2020.

Nogueira, a. L. C. Et al. Avaliação sensorial de água de coco (cocos nucifera I) in natura e processada. Revista de biologia e ciências da terra, v. 4, n. 2, 2004. Disponível em: https://www.redalyc.org/pdf/500/50040219.pdf. Acesso em 08 out. 2021.

Pinto, a. C. L. Et al. Água de coco em pó como suplemento hidroeletrolítico e energético para atletas. Revista brasileira de medicina do esporte, v. 21, n. 5, p. 390-394, 2015. Disponível em:

Https://www.scielo.br/j/rbme/a/4ndwlc67qgcrqmg5vxshhhf/?lang=p acesso em: 5 out. 2021.

Santos, n. B. Análise físico-química e microbiológica da água de coco comercializada na cidade de grajaú, maranhão. Universidade federal do maranhão - ufma, licenciatura em ciências naturais/química. Monografia. 2016.

Socesp. Sociedade de cardiologia do estado de são paulo (são paulo). Teor de sódio na alimentação. $2021 . \quad$ Disponível em: https://socesp.org.br/publico/qualidade-de-vida/nutricao/teor-de-sodio-naalimentacao/. Acesso em: 04 out. 2021. 